\title{
Coexistent neck enteric cyst and intraspinal neurenteric cyst: Embryopathogenetic implications
}

\author{
Ivo Starek', Jan Herman ${ }^{\mathrm{a}}$, Richard Salzman ${ }^{\mathrm{a}}$, Petra Belakovaa, Daniela Skanderova ${ }^{\mathrm{b}}$
}

\begin{abstract}
Introduction. Enteric cysts are very rare conditions, occurring mainly in the posterior mediastinum and posterior neck. Their pathomorphology corresponds with that of intraspinal neurenteric cysts. Both formations are derivatives of the posterior foregut. However, their embryopathogenesis has not been elucidated satisfactorily as yet. For those associated with vertebral anomalies, the split notochord theory has been widely accepted. However, this is be hardly conceivable for cases free of these anomalies.
\end{abstract}

Case report. Here, a patient with concurrent separated enteric and neurenteric cysts and cervical spine dysmorphism is presented.

Discussion. The review of the relevant literature revealed sporadic analogical cases in which a transvertebral communication between the two cysts was present or absent. The latter was associated with a minimal abnormality of the vertebral body.

Conclusion. The authors suggest that normal vertebrae may be formed in patients with enteric cysts, which would make the notochord-split theory plausible also for those free of spinal malformations.

Key words: embryogenesis, cysts, notochord, enteric cyst, neurenteric cyst

Received: February 12, 2020; Revised: July 7, 2020; Accepted: July 7, 2020; Available online: July 15, 2020

https://doi.org/10.5507/bp.2020.030

(c) 2021 The Authors; https://creativecommons.org/licenses/by/4.0/

${ }^{a}$ Department of Otorhinolaryngology, University Hospital Olomouc and Faculty of Medicine and Dentistry, Palacky University Olomouc, Czech Republic

${ }^{b}$ Department of Clinical and Molecular Pathology, University Hospital Olomouc and Faculty of Medicine and Dentistry, Palacky University Olomouc, Czech Republic

Corresponding autor: Petra Belakova, e-mail: petra.belakova@fnol.cz

\section{INTRODUCTION}

Foregut anomalies are sporadic dysembryonal formations. Because of variable anatomical position and histomorphology, they were labeled with different, often confusing terms. In 2009, Sharma et al. proposed a new taxonomy and classification based on a unifying concept of suggested embryopathogenesis, categorizing them as duplication cysts, bronchopulmonary foregut malfomations, bronchogenic cysts and foregut and enteric cysts (ECs) (ref. ${ }^{1}$ ). The latter (also termed enterogenous cyst, endodermal cyst, gastroenterogenous cyst, gastrocytoma, intestinoma, and archenteric cyst, etc.) are considered to be derivatives of the dorsal portion of the foregut that suggests an origin in the upper part of the gastrointestinal tract (including pharynx, esophagus, stomach, duodenum, pancreas, liver and gall bladder). ECs thus comprise two distinct smooth muscle layers and epithelial lining corresponding morphologically with that of the dorsal foregut itself or the viscera originating from it. ECs may be incorporated in various GIT organs or isolated in different locations with a prevalence in the posterior mediastinum and rarely intraabdominaly or in the posterior neck ${ }^{2-11}$. Neurenteric cyst (NEC) is considered to be a variant of EC. It differs from it in occasional presence of ependymal or glial elements, and intraspinal or very rarely, intracranial position. The embryopathogenesis of these cysts has not been elucidated satisfactorily as yet and various theories have been postulated ${ }^{1,3}$. Frequent $(40-70 \%)$ coexistence with spinal anomalies and persistent attachment to the vertebral column suggests that the split notochord theory is at work in the formation of these anomalies ${ }^{12,13}$. However, this theory fails in cases devoid of split notochord syndrome consisting of vertebral malformation associated with central nervous system and gastrointestinal tract anomalies.

Here we describe simultaneous occurrence of a posterior neck enteral cyst and an intraspinal neurenteral cyst. We believe that our case along with those found in the relevant literature will contribute to the embryopathogenesis of these malformations.

\section{CASE REPORT}

A 29-year old woman presented with a history of headaches and neck stiffness. With the exception of an inconspicuous sinistroscoliosis, the ENT examination was within normal limits. MRI of the neck showed congenital synostosis of vertebrae C2-5, a hemivertebra Th1 and a deformation of vertebrae $\mathrm{C} 6$ and 7, which correspond to the MRI findings linked to Klippel-Feil syndrome. Furthermore, two cysts were found (Fig. 1a) with the larger one located in the right posterior neck extending 

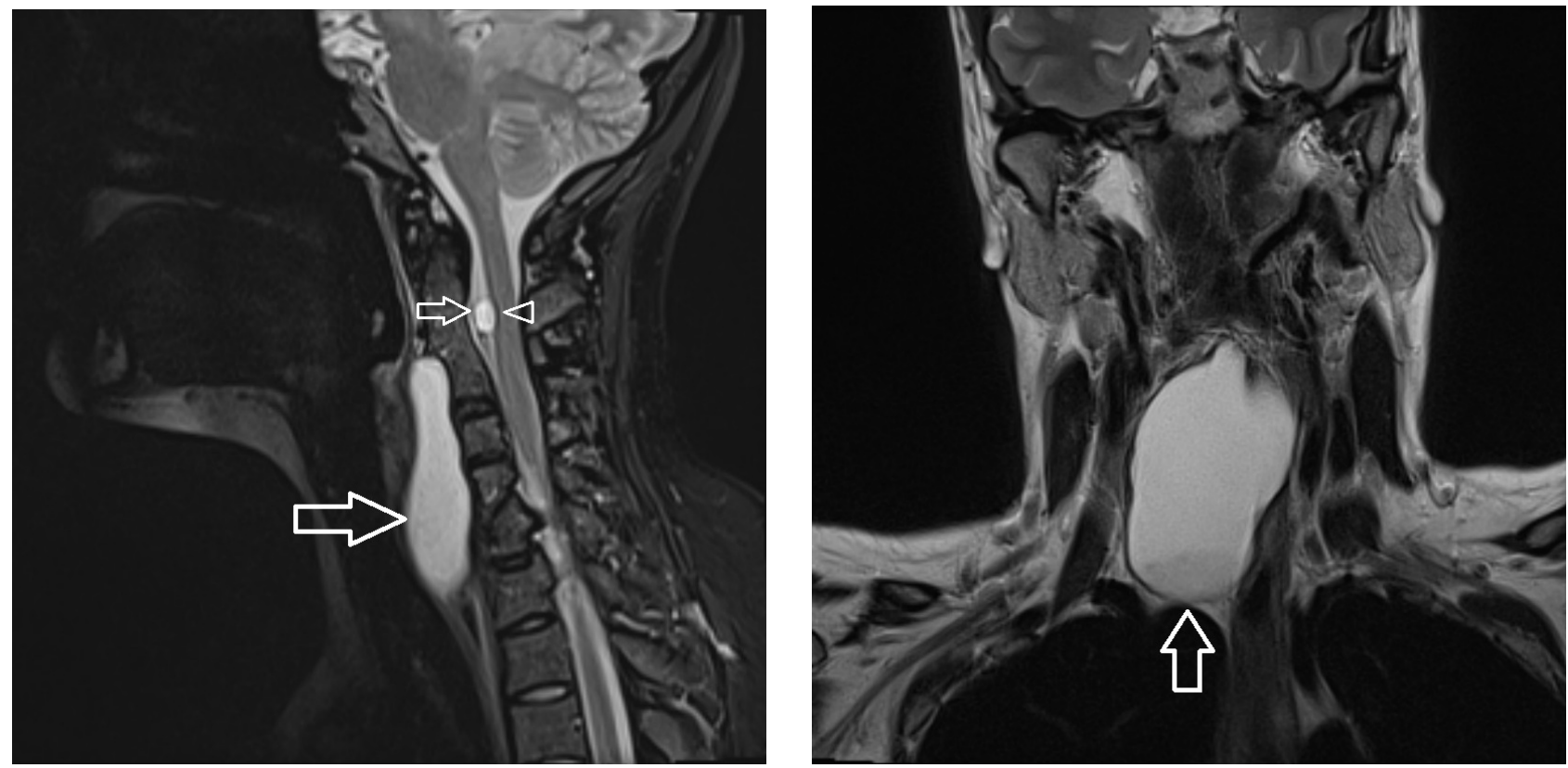

Fig. 1. MRI of the neck: a. sagittal plane, T2 WI. A large prevertebral cyst is seen (great arrow). A C2 presumably intradural extramedullar cyst (small arrow) sized $8 \mathrm{~mm}$ in the greatest diameter is present causing shallow anterior compression of the spinal cord (arrowhead). Both cysts are non-enhancing, well delineated, isointense compared with cerebrospinal fluid in T2 WI. Normal configuration of the $\mathrm{C} 1$ vertebra, $\mathrm{C} 2-\mathrm{C} 4$ posterior synostosis, spina bifida at $\mathrm{C} 5-\mathrm{C} 6$ and hemivertebra $\mathrm{C} 7$; b. coronal plane, $\mathrm{T} 2$ WI. Inferior pole of the neck cyst reaches as far as the thoracic inlet.

down to the Th3 level (Fig. 1b). The longitudinal and transversal diameters were 8 by $4 \mathrm{~cm}$. Another small intraspinal cyst lacking any evident connection with the former was also present. The MRI image of the intraspinal cyst met the MRI criteria of neurenteric cysts, moreover in the presence of Klippel-Feil syndrome ${ }^{14}$. The cervical cyst was removed using an external approach. It was found to overlie but not to communicate with the thyroid trachea and esophagus. There were neither fibrous connections nor communication between vertebrae and the cyst and its complete removal as well as postoperative course was uneventful. Because of the absence of any cord compression symptoms, the intraspinal cyst was left without any neurosurgical intervention. Three years later, the patient is doing well, with no clinical signs of recurrence. Histopathologic analysis of the surgical specimen (Fig. 2) showed a cyst with the wall composed of two layers of a smooth muscle. The cyst was covered with gastric mucosa with continuous transition into a flat non-keratinizing squamous epithelium. No cartilage was found.

\section{DISCUSSION}

Association between ECs and spinal abnormalities, assuming a common mechanism involved in their formation was noticed by some early authors ${ }^{15,16}$. Later, it was conclusively proven by Bently and Smith who postulated the split notochord theory ${ }^{17}$. This suggests primary split of the notochord as the starting formal event in the development of enteric cysts associated with spinal malformations. The split occurs in a three week embryo and is composed of ectodermal, mesodermal and endodermal

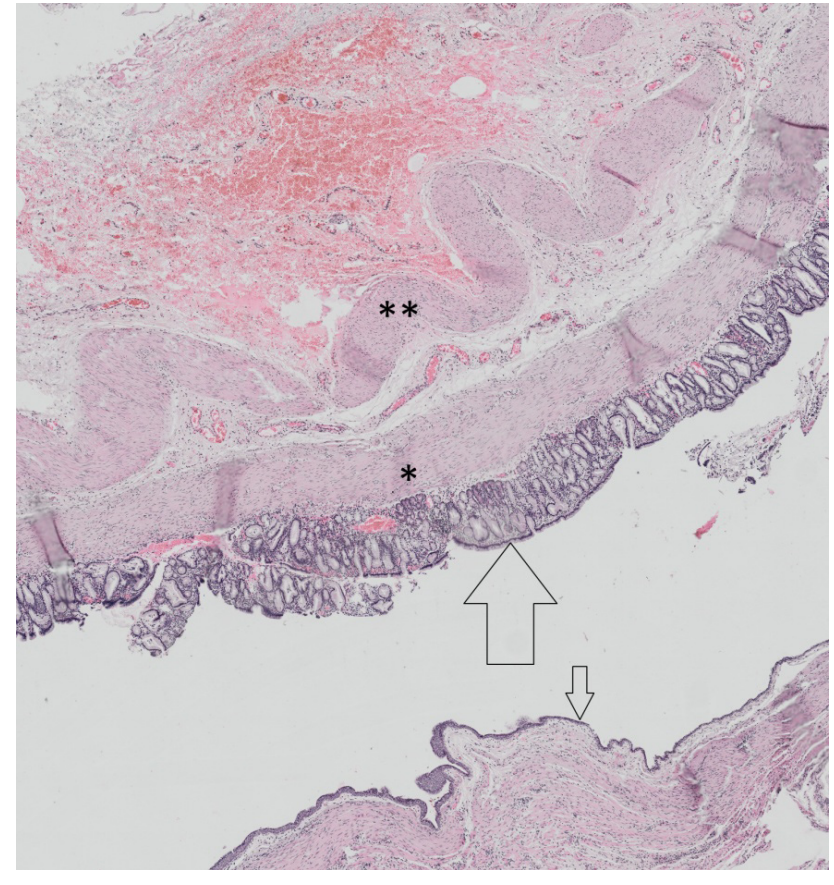

Fig. 2. Pathomorphology of the enteric cyst (H.E.). Inner longitudinal (asterisk) and outer circular (double asterisk) layers of smooth muscle are clearly discernible. The cyst is lined with gastric mucosa, the glands of which are composed of columnar epithelium (large arrow), goblet cells are not present. Large parts of the cyst are covered with a flat non-keratinizing squamous cell epithelium (small arrow). 
layers. The latter gives rise to the notochordal plate. This is temporarily in contact with dorsal ectoderm and escalates later from the endoderm to form solid notochord that is the primordium of the future axial skeleton. In this pathological scenario, herniation of the endodermal diverticulum through the pre-existing notochord gap and its contact with the ectoderm occur. These events, interfering with normal development of vertebrae, spinal cord and relevant viscera, result in anomalies called posterior enteric remnants. Their eventual nature determined by the extent of the herniation may be subdivided into fistulae, sinuses and posterior enteric diverticula and cysts ${ }^{18}$. The latter two formations develop when solely an intermediate part of the endodermal diverticulum persists. The remaining part may become atrophic, leaving a fibrous band connecting the cyst to the anterior aspect of the vertebral body. The more or less complete persistent gap in the dorsal embryonic tissues results in associated various spinal malformations (butterfly vertebra, anterior or posterior spina bifida, Klippel-Feil syndrome, diastematomyelia, meningocoele etc.).

Other mechanisms for development of an endodermal diverticulum may be abnormal escalation of the notochord from the dorsal foregut and persistent neurenteric canal $^{19}$. However, the latter theory is weak. The canal that represents a patent endo-ectodermal passage separating the notochord into two lateral parts is situated in the most caudal aspect of the spine where neurenteric cysts occur very rarely ${ }^{1}$. This drawback eliminates the Bremer's theory of accessory neurenteric canal that occurs in a more rostral position ${ }^{20}$.

These theories are based on the formation of endodermal cells lined diverticulum attached to or separating the notochord. Therefore, they are considered to be applicable only for cysts associated with vertebral malformations. For cases free of them, other more or less acceptable explanations were sought ${ }^{1,21}$.

Shreedhar, Piramoon, Holcomb and Dorsey described posterior mediastinal enteric cysts expanding intraspinally through a hole in distorted vertebral body ${ }^{22-25}$. In our patient, the cysts were associated with spinal anomaly but lacked any apparent transvertebral communication. A similar finding was described by Guillery in a baby who died at the age of 3 months from a congenital heart defect ${ }^{16}$. At the autopsy, however, neither epithelial nor fibrous transvertebral connection between the two cysts was found. The author thus postulated early presence of a cyst between the lateral vertebral anlagen. It later becomes snared into two parts by normal fusion of vertebral masses, with minimal or - as we assume - even no vertebral body malformation and no connection tract left behind. We believe that this hypothesis would explain those cases of isolated enteric cervico-thoracic and intraabdominal cysts published by Andrew, Mahore and Kim, respectively, in which, because of absent spinal dysraphism, the notochord-split theory could seem implausible ${ }^{9-11}$.

Despite the similar pathomorphology of a dorsal foregut formation, it is not quite clear whether ECs and NECs share identical embryopathogenesis ${ }^{24}$. This hypothesis is supported by the simultaneous presence of both types of cysts. They - as it was in our case and in that described by Guillery ${ }^{16}$ - may be entirely separated or communicate through a transvertebral defect ${ }^{22-26}$. In addition, the occurrence of two unrelated dysembryogenetic events in the same patient is hardly conceivable.

\section{CONCLUSION}

The presented case of coexistent foregut intraspinal and cervical cysts lacking transvertebral communication suggests that they may develop without spinal malformation. This makes the split notochord theory plausible also for cases with absent spinal dysraphism.

\section{ABBREVIATIONS}

EC, Enteric cyst; HE, Hematoxylin eosin; NEC, Neurenteric cyst; T2 WI, T2 weighted image.

Acknowledgments: The authors wish to thank Mr. Ing. Ivo Úberall and Miss Berenika Součková for their technical help during production of this manuscript. The study was supported by MH CZ - DRO (FNOL, 00098892) and the Internal Grant of Palacký University IGA LF 2019-20.

Author contribution: IS: manuscript writing. JH, RS, PB, DS: manuscript revision. IS, PB: literature search. JH, RS, PB, DS: final approval. JH, RS: English correction. DS: critical reading.

Conflict of interest statement: The authors state that there are no conflicts of interest regarding the publication of this article

\section{REFERENCES}

1. Sharma S, Nezakatgoo N, Sreenivasan PO, Vanatta J, Jabbour N. Foregut cystic developmental malformation: New taxonomy and classication - Unifying embryopathological concept. Indian J Pathol Microbiol 2009;52:461-72.

2. Beardmore HE, Wigglesworth FW. Vertebral anomalies and alimentary duplications: clinical and embryological aspects. Pediatr Clin North Am 1958;5:457-74.

3. Fallon M, Gordon AR, Lendrum AC. Mediastinal cysts of fore-gut origin associated with vertebral abnormalities. Br J Surg 1954;41:52033.

4. Fernandes ET, Custer MD, Burton EM, Boulden TF, Wrenn EL Jr, Whittle AP. Neurenteric cyst: surgery and diagnostic imaging. J Pediatr Surg 1991;26:108-10.

5. Neuhauser EBD, Harris GBC, Berrett A. Roentgen features of neurenteric cysts. Am J Roentgenol Radium Ther Nucl Med 1958;79:235-40.

6. Nathan MT. Cysts and duplictions of neurenteric origin. Pediatrics 1959;23:476-84.

7. Salyer DC, Salyer WR, Eggleston JC. Benign developmental cysts of the mediastinum. Arch Pathol Lab Med 1977;101:136-9.

8. Veeneklass GMS. Pathogenesis of intrathoracic gastrogenetic cysts. Am J Dis Child 1952;83:500-7.

9. Kim SK, Lim HK, Lee SJ, Park CK. Completely isolated enteric duplication cyst: case report. Abdom Imaging 2003;28:12-4.

10. Andrew R, Ulualp SO, Koral K, Rakheja D, Deskin R. Cervical foregut duplication cyst: a rare neck mass. Int J Ped Otorhinolaryngology 2012; Extra 7:159-61. 
11. Mahore A, Ramdasi R, Popat P, Sankhe S,Tikeykar V. Isolated enteric cyst in the neck. Case Rep Otolaryngol 2014;4:e597813. doi: $10.1155 / 2014 / 597813$

12. Carachi R, Azmy A. Foregut duplications. Pediatr Surg Int 2002;18:371-4.

13. Choi DY, Lee HJ, Shin MH, Kim JT. Solitary cervical neurenteric cyst in an adolescent patient. J Korean Neurosurg Soc 2015;57:135-9.

14. Preece MT, Osborn AG, Chin SS. Intracranial neurenteric cysts: Imaging and pathology spektrum. Am J Neuroradiol 2006;27:1211 16.

15. Stoeckel KN. Über einen Fall von intrathorakaler Entodermcyste im Mediastinum posterius bei einem Neugeborenen. Zbl Gynäk 1935;59:2178-83.

16. Guillery $\mathrm{H}$. Eine in die Wirbelsaule eingewachsene mediastinale Zyste (Vorderdarmzyste). Zbl allg Path and Path Anat 1938;69:49-53.

17. Bentley JF, Smith JR. Developmental posteriori enteric remnants and spinal malformations. The split notochord syndrome. Arch Dis Child 1960;35:76-8.

18. Smith JR. Accessory enteric formations: a classification and nomenclature. Arch Dis Child 1960;35:87-9.
19. Rhaney K, Barclay GPT. Enterogenous cyst and congenital diverticula of the alimentary canal with abnormalities of the vertebral column and spinal cord. J Pathol 1959;7:457-71.

20. Bremer JL. Dorsal intestinal fistula: accessory neurenteric canal: diastematomyelia. Arch Pathol 1952;54:132-8.

21. Stevenson R, Kelly JG, Aylsworth AS, Phelan MC. Vascular basis for neural tube defects: a hypothesis. Pediatrics 1987;80:102-6.

22. Sreedhar M, Menon S, Varma G, Ghosal N. Cervico-thoracic neurenteric cyst - a case report. Indian J Radiol Imaging 2006;16:99-102.

23. Piramoon AN, Abbassioun K. Mediastinal enterogenic cyst with spinal cord compression. J Pediatr Surg 1974;9:543-5.

24. Holcomb GW, Matson DD. Thoracic neurenteric cyst. Surgery 1954;35:115-21.

25. Dorsey JF, Tabrisky J. Intraspinal and mediastinal foregut cyst compressing the spinal cord. J Neurosurg 1966;24:562-7.

26. Wilkins RH, Odom GL. Spinal intradural cysts: in Vinken PJ, Bruyn GW eds. Tumors of the spine and spinal cord. Part II. Handbook of Clinical Neurology. Vol. 20. Amsterdam: North Holland; 1976. pp. 55-102. 